\title{
Sugestões para uma reforma da Lei do Impôsto de Consumo
}

Afonso Borges Filho.

LIGEIRO HISTÓRICO DO IMPÔSTO DE CONSUMO NO BRASIL

A história de nos so impôsto de consumo começa, pràticamente com o advento do regime republicano. E' bem verdade que já no tempo do Brasil colonial conheciamos impostos indiretos, alguns com a feição que haveria de tomar, mais tarde, o impôsto de consumo. E' assim que Vieira Machado (1) vê na Carta de Lei de 1.772 de Dom José, Rei de Portugal, a gênese do referido impôsto. A título de curiosidade, transcreveremos o trecho da Carta de Lei que nos interessa :

Dom José, por graça de Deos, Rei de Portugal, etc. ...

Item II - Mando que para a útil aplicação do mesmo ensino público, em lugar de sobreditas collectas até agora lançadas a cargo dos povos; se estabeleça, como estabeleço, o único Impôsto a saber : ... Na América e África de hum real em cada arretel de carne, da que se corta nos açougues; e nellas e na Ásia, de dez réis de cada canada de agua-ardente das que se fazem nas terras, debaixo de qualquer nome que se lhes dê ou lhe venham dar.

Mas é na primeira lei orçamentária da República (Lei $n^{\circ} 25$ de 30 de dezembro de 1891) que o impôsto de consumo vai aparecer como tal, discriminado na receita ordinária da União. De proporções muito modestas no comêço, já que nesta lei o impôsto recaía apenas sôbre o fumo, cigarros, charutos e rapé, o impôsto de consumo haveria de se transformar, com o tempo, no mais sólido esteio da arrecadação federal. Em têrmos quantitativos, eram essas as taxas inicialmente incidentes sôbre tais produtos:

Fumo em bruto, por 250 gramas ou fração de 250 gramas . . \$ 050

Fumo desfiado, picado ou migado, por 50 gramas ou fração de 50 gramas ......................... \$ 020

Fumo em charutos, por 20 gramas ou fração de 20 gramas. $\$ 020$

Cigarros, por 20 gramas ou fração de 20 gramas ..... \$ 010

Rapé, tabaco ou caco, por 30 gramas ou fração de 30 gramas $\$ 010$

(1) Carlos Vieira Machado, O Impôsto de Consumo no Brasil, p. 17. 
Em 1892, incidindo apenas sôbre o fumo, o impôsto de consumo rendeu Cr\$ 264.836,90. Posteriormente, passaram a ser tributados pelo referido impôsto :

Bebidas - Lei $n^{\circ}$ 359, de 30-12-1895.

Fósforos e sal - Lei $\mathrm{n}^{2} 489$, de 15-12-1897.

Calçados, velas perfumarias, especialidades farmacêticas, conservas, cartas de jogar e vinagre - Lei n? 559, de 31-12-1899.

Chapéus, bengalas e tecidos - Lei $n^{\circ}$ 641, de 14-11-1899.

Aliás, esta última lei foi a primeira a unificar, num único diploma legal, os diversos impostos de consumo. O Decreto $\mathrm{n}^{\circ} 3.535$, de 21 de dezembro de 1899 que "dá Regulamento para a execução da Lei ñ 641 de 14-11-899 e estabelece o processo de arrecadação dos impostos de consumo" é, também, o rimeiro regulamento global dos diversos impostos de consumo. Ali estão discriminadas as diversas formas de cobrança do tributo, as penalidades em que incorrerão os contraventores, os direitos e deveres dos agentes fiscais, etc. Mas os produtos sujeitos ao impôsto de consumo não cessam de aumentar; é assim, que, paulatinamente entram na órbita tributária :

Vinhos estrangeiros - Lei $\mathrm{n}^{\circ} 1.313$ de 30-12-904.

Café torrado artificial - Lei $\mathrm{n}^{\circ} 1.616$ de 30-12-906.

Manteiga e banha nacionais e artificiais - Leis ns. 1.616 de $30-12-906$ e 2.321 de $30-12-910$.

Espartilhos, papel para forrar casas, discos para gramofones, louças e vidros - Lei n 2.919 de 31-12-914.

Ferragens - Lei $n^{\circ} 3.070$ de 31-12-915.

Pilhas elétricas sêcas nacionais: Lei $\mathrm{n}^{2} 3.644$ de 31-12-918.

Em 1920, a arrecadação do impôsto de consumo assume a cifra de $\mathrm{Cr} \$ 175.635 .589,90$. Mas a esta época, com uma economia ainda tipicamente colonial, o esteio da arrecadação federal continua sendo o impôsto de importação. Sòmente a partir de 1940 o impôsto de consumo haveria de sobrepujar o impôsto de importação.

Eis um quadro comparativo da arrecadação dos impostos de consumo e cle importação em alguns anos do decênio 1931-1940 :

\section{Cr $\$ 1.000,00$}

\begin{tabular}{|c|c|c|c|}
\hline & Ano & Importação & Consumo. \\
\hline 1932 & 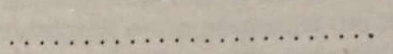 & 527.275 & 388.579 \\
\hline 1936 & $\ldots$ & 1.012 .105 & 606.024 \\
\hline 1938 & $\cdots$ & 1.052 .562 & 889.000 \\
\hline 1939 & .......... & 1.031 .197 & 1.029 .688 \\
\hline 1940 & $\ldots \ldots \ldots$ & 977.514 & 1.054 .000 \\
\hline
\end{tabular}

O decréscimo relativo da importância do impôsto de importação no quadro orçamentário da União nos anos subseqüentes é decorrência não sỏmente das dificuldades de importação geradas pela segunda grande guerra mundial, como também da incessante industrialização do país. Sob êste 
aspecto, o fato é altamente promissor, pois indica que o Brasil ensaia os primeiros passos para ascender da classe dos países subdesenvolvidos para a dos países semidesenvolvidos. Realmente, como salienta Pierre Moussa (2) a politica fiscal dos países subdesenvolvidos se caracteriza pelo fato de assentar a base de seus recursos orçamentários nos impostos de importação e exportação (3). Para se ter uma idéia de como tem regredido a importáncia relativa do impôsto de importação, entre nós, basta dizer que, em 1957, para uma receita tributária da ordem de $\operatorname{Cr} \$ 67.429 .000 .000,00$, o impósto de importação contribuiu com a insignificante parcela de ........ Cr\$ $1.937 .000 .000,00$, figurando o impôsto de consumo em $\ldots \ldots \ldots \ldots$. Cr\$ 30.481.000.000,00 e o impôsto de renda com Cr\$27.018.000.000,00 (4). E' bem verdade que o âmbito de incidência do impôsto de consumo se amplia cad̉a vez mais. Já em 1938 (Decreto-lei n 739 de 24 de setembro), a lista de produtos sujeitos ao referido impôsto ascende a quarenta e um, assim discriminados : 1 - Fumo: 2 - Bebidas: 3 - Álcool; 4 - Fósforos e isqueiros; 5 - Sal; 6 - Calçados; 7 - Perfumarias e artigos de toucador; 8 - Especialidades farmacêuticas; 9 - Conservas; 10 - Vinagre e óleos adequados à alimentação; 11 - Velas; 12 - Tecidos; 13 - Artefatos de tecidos e de peles; 14 - Papel e seus artefatos; 15 - Cartas de jogar; 16 - Chapéus e bengalas; 17 - Louças e vidros; 18 - Ferragens (artefatos de ferro e de outros metais; 19 - Café torrado ou moído e chá; 20 Banha, manteiga e sucedâneos: 21 - Móveis: 22 - Armas de fôgo, suas munições e fogos de artifício; 23 - Lâmpadas, pilhas e aparelhos elétricos; 24 - Queijos e requeijões; 25 - Eletricidade; 26 - Tintas e vernizes; 27 - Leques; 28 - Artefatos de borracha; 29 - Pincéis para barba e obra de cutelaria; 30 - Pentes, escôvas, espanadores e vassouras; 31 - Brinquedos; 32 - Artefatos de couro e de outros materiais; 33 - Jóias e obras de ourives; 34 - Bijuterias; objetos de adôrno e de utilidade e relógios; 35 - Gasolina, óleos e carbureto de cálcio; 36 - Ladrilhos e outros materiais; 37 - Instrumentos de música; 38 - Material ótico, fotográfico e cinematográfico; 39 - Fogões, fogareiros e aquecedores; 40 - Cimento, e 41 - Linhas, cordoalhas e botões.

(2) Pierre Mousa, Les Nations Prolétaires, Paris, 1959, p.33-34.

(3) LuCien MeHL extraiu as seguintes regras dos trabalhos de Masoin e Brochier : 1. - A proporção das receitas aduaneiras no conjunto dos impostos sôbre as despesas é tanto mais fraca quanto mais evoluida é a economia. Em 1948: Egito, 80\%; Colômbia, $45 \%$, Gră-Bretanha, Estados Unidos, $5 \%$. $2^{\circ}$ - Os paises que acusam uma forte proporção de impostos específicos sôbre a circulação ou o consumo no conjunto dos impostos sôbre as ciespesas são: os países sub-desenvolvidos em que o impôsto sôbre as transaçôes não foi ainda instituido por falta de estrutura econômica adequada (Em 1948: Irã, 58\%: Colômbia. $65 \%$; Filipinas, $88 \%$ ); ou países em que o impôsto sôbre transações desempenham um papel secundário ou mesmo nulo (Suécia), em virtude da preponderância assumida pelo impôsto de renda e neste caso os impostos de consumo são mantidos a titulo complementar. incidindo, sobretudo, sôbre artigos de luxo (em 1948: Reino Unido, 76\%; Estados Unnidos, $66 \%$. Suecia, 91\%). (Science et Technique Fiscale, Paris, 1959, vol. I, p. 221).

(4) Com a reforma introduzida pela nova lei de tarifa, o impôsto de importação tende a crescer novamente. Para 1959, em que o total da receita tributária foi orçado em 128.472 nuilhões, o referido impôsto foi estimado em 24.032 milhões. Isto, porém, não infirma as considerações sôbre o desenvolvimento e o progresso industrial do pais. 
Note-se que, o legislador tivera o cuidado de individualizar precisamente - produto tributado, adotando, sob êste aspecto, a técnica do "Purchase ' $\mathrm{dx}$ " vigorante na Inglaterra. Mesmo quando a incidência parece mais generalizada, como nos casos, por exemplo, dos números 32 (Artefatos de couro e de outros materiais) e 34 (Bijuterias, objetos de adôrno e de utilidade e relógios) os "artefatos de outros materiais", e os "objetos de adôrno e de utilidade" vêm minuciosamente discriminados. Aliás, esta preocupação de definir a matéria tributada é uma constante que se nota em tôdas as refornıas da lei do impôsto de consumo levadas a efeito até 1938. A Lei n 2.919 de 31 de dezembro de 1914 que instituiu o impôsto sôbre louças e vidros esclarece que as louças tributadas são as que constam da classificação da tarifa, ns. 646 e 651 , primeira parte da classe 21 e os vidros são os que constam da mesma tarifa, mesma classe, ns. 661 e 666. A Lei n 3.070 A, de 1915 que criou o impôsto sôbre ferragens estabelece : a) parafusos, pregos, taxas, arestas e arrebites de ferro ou de aço, simples, Constantes dos arts. 749 e 751 da Jarifa, por 250 gramas ou fração: $\$ 010 ; b$ ) idem, idem com cabeças de outra qualquer matéria, Constantes dos arts. 749 e 751 da Tarifa, por 250 gramas ou fração: \$015; e assim por diante. Essa preocupação do legislador era altamente louvável, pois diminuia em grande parte as possibilidades de atrito entre fisco e contribuinte. Evidentemente, não pretendemos afirmar que as leis sôbre o impôsto de consumo promulgadas até 1938 eram perfeitas. A imperfeição é uma contingência da criação humana. O que desejamos salientar é que já àquela época, havia um critério firmemente perseguido felo legislador e que êste critério estava apoiado num sadio princípio de ciência econômica qual seja o da certeza e simplicidade do impôsto.

A primeira reforma estrutural do nosso impôsto de consumo ocorreu com o advento do Decreto-lei $n^{\circ} 7.404$ de 22 de março de 1945 . Os produtos tributados foram distribuidos em vinte e nove alineas e agrupados em quatro tabelas cada uma com suas normas de regência especificas. $O$ âmbito de incidência alargou-se enormemente, embora os quarenta e um produtos anteriormente discriminados houvessem sido reduzidos a vinte e nove alíneas. Adotou-se pela primeira vez, o critério de tributação por grupo de produtos, tendo em vista a matéria prima de que eram fabricados. Sòmente as alineas I (Aparelhos, máquinas e artefatos de metais) e III (Artefatos de matérias de origem animal e vegetal) fizeram entrar no âmbito tributário milhares de produtos até então não alcançados pelas malhas fiscais. A fim de evita: o fenômeno da incidência do impôsto em cascata, foram exonerados do tributo, de um modo geral, as matérias primas destinadas à confecção dos produtos acabacios. E' assim que, na alínea I foram exonerados os arames e fios nus de qualquer espécie e formato; as barras vergalhões, cantoneiras, laminados, trifilados ou perfilados de qualquer espécie e formato, tubos de qualquer espécie e suas conexões; trilhos, chapas, discos e tiras de qualquer espécie não fundidos; blocos, pacotes, pães e pedaços destinados a fusão ou transformação etc. E ainda denotando uma alta compreensão de política fiscal, o legislador exonerou, também, as máquinas operatrizes e aparelhos destinados à produção industrial. 
Claro está que não se pode admitir tenha a reforma de então pretendido simplesmente rácionalizar a cobrança do impōsto. Na verdade, êste tornou-se mais complexo. O que se objetivava era um maior rendimento fiscal para satisfazer às crescentes necessidades do Estado. Aliás, o desmesurado crescimento das despesas estatais nas últimas décadas é um fenômeno universal. J. Marchal, (5) analizando o fato explica o como uma decorrência da transformação do capitalismo no mundo. Diz que, no comêço dc século XIX, o capitalismo é "atômico". A atividade econômica resulta da ação entre individuos sem ligações uns com os outros. Estabelecer a ordem no iriterior, defender o país contra o estrangeiro são pràticamente, as únicas funções estatais. E o Estado-gendarme, o Estado-soldado da concepção libera!. Hoje, o capitalismo tornou-se "molecular". A atividade econômica resulta não mais de uma justaposição, mas de uma associação de esforços individuais. No interêsse geral, o Estado viu-se obrigado a intervir. Suas funções deixaram de ser sòmente politicas para serem também econômicas. E com suas funções multiplicadas, multiplicaram-se, também, as suas necessidades. Na França, o orçamento foi de 4.700 milhões em 1913. Passou para 45.300 milhões em 1929 e hoje em dia é de algumas centenas de bilhões. No Brasil, a receita orçamentária em 1907 foi de 534 milhões. Em 1947 alcançava a cifra de 13.853 milhões e já ultrapassou, atualmente, a casa da centena de bilhões.

As enormes tarefas a que se propõe o Estado para melhorar o padrão de vida da comunidade obriga o a avançar cada vez mais no patrimônio privado dos cidadãos, procurando, de uma certa maneira, corrigir a distribuição da riqueza que, num regime capitalista, dado o primado da iniciativa privada e da competição individual, há de ser, forçosamente desigual. Vê-se, assini, que o impôsto passou a ter, nos dias atuais, um caráter eminentemente socializante. (5-A) Nos Estados Unidos, o impôsto de renda, depois de uma certa faixa, chega a "eliminar" $91 \%$ dos lucros do cidadão, o que é quase um confisco. Entre nós, a aliquota progressiva máxima do impôsto

\section{(5) Jean Miarchal, Rendements Fiscaux et Conjuncture, p. 13 e seg.}

(5-A) Na verdade, muitos economistas modernos pretendem chegar à construção do socialismo quase que exclusivamente mediante a manipulação dos impostos. DougLAs JAY, na Inglaterra, imaginou poder chegar-se ào socialismo por três degraus. O primeiro é a taxação da renda e da herança dos ricos para formar recursos destinados aos serviços sociais ; o segundo é "uma larga escala de planejamento deliberado por meio de impostos, subsidios, contrôle de preços, produção destinada a satisfazer as necessidades naturais do homem, etc.; e o terceiro, a nacionalização de alguns dos setores industriais financeiros e comerciais. êle :

O primeiro degrau é o que se pode considerar como verdadeiramente socialista. Diz

"Podemos considerá-lo como uma casa a meio do caminho do socialismo. Em verdade, é mais do que a metade do caminho, pois a utilização da renda não merecida, para elevar o padrão de vida dos mais pobres, que vivem do salárid, deverá constituir sempre o âmago verdadeiro do socialismo. Por isso, todos os que consideram a competição e os preços não regulados como o supremo valor econômico deveriam observar que podem apoiar essa etapa do socialismo sem abandonar os seus principios". (JoHn EATON MARX contra KEYNES, tradução brasileira de Gilberto Paim, p. 89). 
complementar é de $50 \%$ para as rendas liquidas superiores a três milhões de cruzeiros. Na Inglaterra certos produtos que não estão ao alcance de todo - mundo e que, portanto, são considerados de luxo, são tributados pela "purchase tax" na base de $60 \%$ "ad-valorem", como é o caso dos automóveis, e dos aparelhos de televisão, enquanto que os relógios, artigos de esporte e jogos e produtos farmacêuticos estão tributados na base de $30 \%$.

A complexidade das funções estatais atuando sôbre todo o mecanismo social teria, forçosamente, que influenciar as leis de impostos. Neste trabalho, dedicado tão sòmente ao estudo atinente ao impôsto de consumo no Brasil, tentaremos analisar o que já se fêz com relação à matéria e quais as possibilidades que se nos apresentam de fazer de tal impôsto um verdadeiro instrumento de progresso social. Não convém, todavia, depositar demasiadas esperanças na ação corretiva ou mesmo norteadora da política fiscal para obviar distorções estruturais ou crises conjunturais. (6) Sobretudo se se tem em mira apenas o impôsto de consumo. Mas é certo que o impôsto pode atuar sôbre a conjuntura. Lucien Mehl (7) explica que a ação do impôsto sôbre a conjuntura pode ser espontânea ou dirigida. Exemplo característico da ação espontânea ou automática é o dado pelo impôsto progressivo sôbre a renda: limitando as possibilidades de poupança e de investimento, quando as rendas crescem, o impôsto ténde a frear a ascensão da conjuntura e a se opor ao "boom". Inversamente, em período de depres sâo, o impôsto progressivo decresce mais que proporcionalmente, do que resulta sobrarem disponibilidades para uma retomada de posição. O sistema fiscal desempenharia, assim, o papel de um termostato, segundo a fórmula d eHenri Gutton. (8) Se se quiser adotar uma politica fiscal anticíclica. necessário será ajuntar aos efeitos compensadores espontâneos do impôsto progressivo sôbre a renda, medidas complementares, como, por exemplo, a manipulação das aliquotas dos diversos impostos. Na fase ascendente da conjuntura, serão aumentados as aliquotas dos impostos de consumo, de vendas e consignações e do impôsto sôbre a renda, de modo a diminuir, concomitantemente, a poupança e o consumo. E na fase de depressão, inversamente, as aliquotas de tais impostos serão diminuídas. Isso permitırá não só o aumento do consumo como a criação de possibilidades novas de irvestimento.

Uma política fiscal global que se adaptasse automàticamente à conjuntura seria, realmente, o ideal. Mas numa sociedade democrática e capitalista êste ideal é inatingível : $1^{\circ}$ - porque num regime democrático não se

(6) Il est dificile d'exercer sur l'économie une influence direcrice à l'aide de la fisccalité, parce que les impôts son des instruments conçus pour prélever et non pour guider. La fiscalité est une chirurgie, non pas du corps, mais du porte-feuille (ce qui n'est pas loin d'être pire). Or on de dirige pas avec un bistouri: on tranche Il parait donc préférable que la fiscalité soit le dernier moyen de direction à utiliser; celui auquel on recourt lorsque les autres ont échoué. (Maurice Lauré, Traité de Politique Fiscale, Paris, 1956, p. 320!.

(7) LucIEN MeHL, op. cit. pág. 265).

(8) H. Gurrton, Finances et cycle Public Finance, $\mathrm{n}^{\circ} 1,1954$. 
pode furtar ao congresso o direito de votar as leis de impostos e estabelecer as alíquotas de incidência. No Brasil, a atual lei de tarifas, dando competéncia ao Conselho de Política Aduaneira para aumentar ou diminuir as aliquotas incidentes sôbre os produtos importados é uma exceção à regra. Note-se, porém, que a própria Constituição, em seu art. $141, \S 34$, estabelece um regime jurídico especial para as tarifas aduaneiras; $2^{\circ}$ ) porque num regime capitalista as crises cíclicas são normais e de duração imprevisível. Poderia dar-se o caso de as medidas anticíclicas serem votadas quando a conjuntura já evoluísse noutro sentido. Para quem está a par da morosidade com que as leis são votadas no Congresso, esta afirmação não constitui nenhuma novidade.

Como ensina Paul A. Samuelson, (9) em condições de desemprêgo, a "tentativa de poupar" poderá resultar em "menos" e não em mais poupança. Se todos tentam entesourar dinheiro, não poderão evidentemente, conseguir todos êsses objetivos, mas a tentativa resulta em uma diminuição da velocidade de circulação do dinheiro e da renda nacional. Assim, quando há desemfrêgo, consumo e investimento são colaboradores e não rivais. $O$ que ajuda a um, ajuda ao outro. Em tal conjuntura, aumentar impostos, diminuindo a capacidade de consumo e de investimento, seria, simplesmente, loucura.

Nosso impôsto de consumo, até 1945, era assentado quase todo em bases especificas. Como ensina Louis Trotabas (10) o têrmo específico, em ruatéria fiscal significa o impôsto que é lançado tendo em vista a unidade naterial do objeto da tributação. Esta unidade pode ser estabelecida em pêso, em superfície (metro quadrado), em volume ou em quantidade (unidade, dúzia), etc. Em oposição ao impôsto específico, está o impôsto "ad-valorem" que recai sôbre o valor do produto. Pois bem. Dos quarenta e um produtos discriminados no Decreto-lei n? 739 de 24 de setembro de 1938, apenas seis pagavam o impôsto "ad-valorem". Dentre êstes, dois (fumo e calçados) estavam tributados na base de seu prêço de venda no varejo. Perfumarias, especialidades farmacêuticas e conservas, por exemplo, estavam tributados à base de seu pêso em gramas. Ora, os impostos específicos são inelásticos e indiferentes à conjuntura. Em período inflacionário, seu rendimento deteriora-se face à desvalorização da moeda e os governos se vêm obrigados a aurientar as taxas de incidência o que provoca sempre clamores e amiúda os atritos entre o fisco e os contribuintes. A reforma da lei do impôsto de consumo em 1945 (Decreto-lei $n^{\circ} 7.404$, de 22 de março) deu, pois, um grande passo para a frente ampliando a área de produtos sujeitos ao impôsto "ad-valorem". De fato, das vinte e nove alineas em que se agrupavam os produtos tributados no referido Decreto-lei, apenas oito mantiveram a taxação especifica. A reforma de 1945 foi, assim, um tento lavrado no que se refere à técnica tributária, embra o impôsto tivesse perdido a simplicidade que o caracterizara até então. Mas nem nisto se pode criticar o legislador. De um certo modo, a complexidade das leis de impostos, como vimos, é uma resultante da complexidade das funções do Estado moderno.

(9) Paur A. Samuelson, Introdução à Análise Econômica, Rio, 1955. Vol. II, p. 36).

(10) Lours Trotabas, Science et Tchnique Fiscales, Paris 1958, p. 25). 
Há mesmo um aforismo que diz: impôsto simples, impôsto injusto, Este aforismo, derivado da afirmação de Voltaire - «impôt unique, impôt inique" - não deixa de ter o seu conteúdo de verdade. Nada mais simples, por exemplo, do que o impôsto de "capitação" e nada também, mas injusto. $\mathrm{O}$ impôsto de capitação é próprio das sociedades primitivas e o seu fundamento é a simples "existência" do contribuinte ou a sua residência no território do Estatdo. E' o impôsto que comporta o máximo de injustiça, afirmam Julien Laferrière e Marcel Waline (11) pois que, por definição, exige a mesma contribuição de indivíduos que estão em situação de fortuna totalrnente diferente. Da mesma maneira são injustos e iníquos o impôsto único sốbre a terra preconizado pelos fisiocratas do fim do século XVIII, o impôsto único sôbre o capital ou o impôsto único sôbre a energia defendido ainda em nossos dias por Eugène Shueller. Para Maurice Duverger (12) nenhum sistema fiscal é perfeito: todos apresentam defeitos mais ou menos graves.

Essas afirmações, aparentemente desanimadoras, não nos devem, porém, levar ao pessimismo. Se um sistema fiscal perfeito é hoje simples miragem, amanhã poderá ser uma realidade concreta.

Depois da reforma de 1945 , a primeira alteração importante introduzida na lei do impôsto de consumo foi a decorrente da Lei $n^{2} 2.974$, de 26 de novembro de 1956 . Nesse interregno houve, sem dúvida, diversas alterações da lei, mas que se limitaram a modificar aliquotas ou estabelecer medidas de contrôle. A Lei $n^{\circ} 2.974$, porém, foi mais profunda: alterou o sistema de tributação de móveis, calçados e jóias, transformou em "ad-valorem" o impôsto anteriormente especifico incidente sôbre cerveja, chope, refrigerantes, cartas de jogar, lâmpadas elétricas e guarda-chuvas, estabeleceu novo sistema de percepção de tributo para os produtos estrangeiros e criou uma série de medidas de contrôle, algumas das quais, embora ainda mantidas no texto da lei, não foram postas em execução por considerar a própria administração que eram excessivamente complexas e onerosas para os contribuintes e para ela própria.

Como a maioria das inovações introduzidas pela Lei $n^{2} 2.974$ foram mantidas pela Lei $n^{\circ} 3.520$ de 30 de dezembro de 1958, posteriormente regulamentada pelo Decreto n 45.422 de 12 de fevereiro de 1959 , deixaremos para o capitulo seguinte, a análise dos referidos diplomas legais.

\section{CRÍTICA ̊̀ REFORMA DE 1958}

Como vimos, depois da grande reforma de 1945 a primeira alteração da lei do impôsto de consumo realmente importante foi a decorrente da Lei $\mathrm{n}^{\circ}$ 2.974, de 26 de novembro de 1956 . Tendo resultado de uma investida

(11) Julien Laferrière et Marcel Waline, Traité Elémentaire de Science et de Législation Financiéres, Paris, 1952, p. 254.

Maurice Duverger, Institutions Financières, Paris, 1957. 
infrutifera do Poder Executivo (12-A) para alterar o sistema anterior, nela já se notam os germes da grande reforma que viria se concretizar dois anos depois, com a Lei $n^{\circ} 3.520$, de 30 de dezembro de 1958. A paternidade intelectual desta Lei n? 3.520 pode-se atribuir ao economista Dr. Gerson Augusto da Silva embora grande tenha sido o número de assessôres técnicos da Diretoria das Rendas Internas que o coadjuvaram. A se deduzir da explanação feita pelo Dr. Gerson Augusto da Silva na reunião conjunta das Comissões de Orçamento e de Finanças da Câmara dos Deputados em 30 de outubro de 1958 (13) - explanação esta que parece ter sido decisiva para a aprovação do projeto de lei que veio a ser mais tarde, a Lei $n^{\circ} 3.520$ pode-se concluir que os objetivos colimados pelos autores da reforma eram : 19) fazer do impôsto de consumo um instrumento capaz de responder às solicitações do Govêrno em matéria de orientação de política econômica; 2:) empregar, na discriminação dos produtos tributados, a técnica da nomenclatura tarifária, por sua vez vinculada à nomenclatura de mercadorias de Bruxelas; $3^{\circ}$ ) evitar a incidência sucessiva do tributo nos produtos intermediários da fabricação, adotando-se para isto o princípio adotado pelo legislador francês (14) que permite ao contribuinte deduzir do impôsto a pagar o impôsto que lhe foi faturado quando da aquisição da matéria prima, e $4^{\circ}$ ) tornar simples a percepção do tributo e equânime a distribuição da carga fiscal.

Sem dúvida, os objetivos perseguidos eram excelentes. Resta, porém, indagar, friamente, se os resultados obtidos justificariam o entusiasmo otimista dos propugnadores da reforma.

Antes de mais nada convém ressaltar que o impôsto de consumo, por si só, - mòrmente se considerarmos que não é êle o impôsto indireto que mais onera o contribuinte brasileiro (15) - dificilmente se prestaria para servir de instrumento de politica econômica do govêrno. Ísto não importa em deixar de reconhecer que a estrutura de impôsto de consumo era já arcaica e incondizente com a nossa realidade econômica. Sob êste ponto de vista, o trabalho dos autores da reforma foi altamente meritório, porque chamou a atenção para um aspecto do fenômeno tributário brasileiro que estava a requerer urgente revisão. Mas os impostos indiretos, mesmo considerados em conjunto, são os que menos se prestam à correção dos ciclos da conjuntura e, portanto, os resultados de sua manipulação para fins de política

(12-A) A primeira tentativa de alteração de nossa lei do impôsto de consumo, dando-lhe a estrutura atual, ocorreu na legislatura de 1956, com o substituto apresentado pelo Deputado Û́ltimo de Carvalho e que, como projeto de lei, tomou o número 1.346. A esta época, era Diretor das Rendas Internas o Dr. Gerson Augusto da Silva, a quem se deve a inspiração do referido projeto de lei.

(13) Diário do Congresso, Seção I de 14 de dezembro de 1958.

(14) A Taxe sur la Valeur Ajoutée vigorante na França é um misto de impôsto " de consumo e de vendas e consignações e resultou da fusão da antiga "taxe à la production" às diversas "taxes uniques" incidentes sôbre determinados produtos.

(15) Em 1957, a arrecadação do impôsto de vendas e consignações, em todo o Brasil, totalizou 44.370 milhões de cruzeiros, enquanto que o impôsto de consumo atingiu a cifra de 30.481 milhões (Rev. de Finanças Públicas, $\mathrm{n}^{\circ}$ 201) 
econômica devem ser encarados com objetividade, sem otimismos exagerados. No caso, por exemplo de uma situação conjuntural ascendente em que, teòricamente, se justificaria a elevação das aliquotas de incidência para forçar a redução do consumo, tal medida, além de antipática, poderia avivar o processo inflacionário pela alta generalizada dos preços que provocaria. Gerhard Colm, (16) analisando o pensamento de Keynes sôbre politica fiscal, extrai as seguintes conclusões: a) em vista do caráter hipotético de todo prognóstico especifico, não é possível formular nenhuma regra dogmática de politica fiscal. Esta deve basear-se na análise especifica das circunstâncias econômicas: b) a politica fiscal é um meio, mas não o único, de levar a cabo uma ação equilibradora. Keynes considerava a formulação de um programa de inversão nacional como a medida mais importante para uma ação aquilibradora e a politica tributária destinada a reduzir as desigualdades na distribuição da renda e a reduzir a poupança em maior medida que os gastos, como a que se seguia em importância. Para se chegar a êste objetivo, dever-se-ia imaginar um sistema tributário progressivo em que a renda que se economiza fôsse gravada mais fortemente do que aquela que se gasta, freiando-se, assim, a diminuição da propensão a consumir.

Da explanação feita pelo Dr. Gerson Augusto DA Silva na reunião conjunta das Comissões de Orçamento e Finanças da Câmara dos Deputados, parece ressaltar que o ilustre economista tinha em vista os ensinamentos de Keynes ao acenar com a possibilidade de uma distribuição seletiva da carga fiscal, tendo em vista a classificação da população do pais em categorias de consumidores ou - o que dá no mesmo - a classificação dos produtos tributacios em categorias decorrentes da maior ou menor generalidade de seu consumo. Isto que seria praticável numa economia planificada de tipo socialista como na U.R.S.S. é de todo impossivel entre nós, devido à complexidade que o sistema acarretaria. Realmente, na Rússia, onde as regras básicas da produção capitalista permanecem tão válidas como no mundo ocidental (17), o impôsto sôbre transações (impôsto de consumo e de rendas e consignações) comportava em 1930, cêrca de 1.200 aliquotas estabelecidas em escala progressiva e variando não só em função da qualidade do produto, como do lugar em que era vendido (18). Como salienta Henry Laufenburger a técnica progressiva do impôsto sôbre a despesa permite ao gnvêrno adaptar o esforço fiscal requerido ao nivel das rendas presumido pelo gênero de despesa. Nestas condições, o impôsto progressivo sôbre a renda não desempenha senão um papel complementar para comprimir a hierarquia das rendas recomendada pela preocupação e segs.

(16) La Nueva Ciencia Econômica, Madrid, Revista de Occidente, S. A., ps. 333

(17) "Considerando que os medidores comuns não poderiam ser estendidos a tôda a vida econômica (serviços de administração, atividades intelectuais inclusive) e que o elemento "tempo de trabalhos socialmente necessário" não exprimia senão uma fórmula abstrata, e economia soviética teve de manter a moeda, o mercado, e mesmo as rendas capitalistas. No fundo, não fêz outra coisa que não rebatizar os elementos da economia socialista". (BERnARD PAJISTE, Produção à Política Fiscal, Edições Financeiras S. A., p. 93).

(18) Henry Laufenburger, Finandes Comparées, Paris, p. 213). 
de assegurar a rentabilidade de produção dos bens e serviços. Note-se, porém que nos regimes socialistas, onde não há emprêsas privadas, a tendência é para a abolição total dos impostos, tendo sido esta uma das promessas de Kruchev no 21. Congresso do Partido comunista realizado em Moscou em 1959. (18- A).

O exemplo da Inglaterra citado pelo ilustre economista Dr. Gerson Augusto da Silva na reunião conjunta da Câmara dos Deputados não foi dos mais felizes: $1^{\text {i) }}$ porque ali o impôsto de consumo (purchase tax) desempenha um papel relativamente insignificante no quadro da receita tributária do país $(19) ; 2^{\circ}$ ) porque a realidade não confirma a perfeição técnica do tributo retratada pelo ilustre economista. Eis a maneira como retratou a situaçấo na Inglaterra conforme consta da publicação no Diário do Congresso, Secção I, de 14 de dezembro de 1958 :

“... Esta forma ideal foi feita na Inglaterra, segundo a qual a população foi dividida em níveis de renda : familias de renda até 60 mil cruzeiros: de 60 a 90 mil : de 90 a $120 \mathrm{mil}$; de 120 mil a $200 \mathrm{mil}$ : de $200 \mathrm{mil}$ a $300 \mathrm{mil} \mathrm{e}$ assim por diante. Depois procurou-se saber quais os bens que compunham a estrutura do consumo de cada classe. Na classe 1 entrava tal quantidade de bens; na classe 2, entrava essa quantidade mais tais bens; na classe 3, aquêles da classe anterior mais outros e assim por diante.

$\mathrm{Na}$ base dessa amostragem foram divididcl em cinco escalas os bens de consumo segundo a sua incorporação nos hábitos de consumo das classes dos niveis de renda mais altos. Com êsse sistema os produtos ficaram escalonados em cinco grupos: bens de consumo absolutamente genérico; bens incorporados às classes números 2,3 e 4 ; e bens que apareciam sempre como consumo natural da classe número 5: e o impôsto de consumo foi dividido em cinco faixas: produtos isentos, produtos sujeitos ao impôsto de $25 \%$. de $50 \%, 75 \%$ e $100 \%$.

Esse sistema prevê inclusive a possibilidade que tem o poder aquisitivo de modificar a categoria de um produto, se as estatísticas revelarem a sua transferência de bens de consumo de classes menores para maiores. Vamos admitir que, segundo as estatisticas, as geladeiras estivessem classificadas no nivel 3, mas que, com o aumento de consumo, uma amostragem feita cinco anos depois revelasse que ela passou para a categoria 2. Então, automàticamente o impôsto baixa, porque ela passou a ser produto que entrou nos hábitos de consumo genérico".

Ainda mesma deixando de contestar a automaticidade na diminuição ou aumento das aliquotas - parece pouco provável que isto aconteça na Ingla-

(18-A) Resumo do Discurso de Kruchev publicado no jornal "Le Monde" de Paris em 28-1-59.

(19) Em 1953, para uma receita tributária de 4.196 milhares de libras, a Purchase Tax contribuiu com apenas 306 milhares (Apud Lucien Mehl, Science et Technique Fiscales, II vol., Paris, 1959, p. 605). 
terra - podem-se apontar inúmeros exemplos em que a "Purchase Tax" tributa arbitràriamente diversos produtos, sem nenhum objetivo visivel senão 0 de proporcionar rendas ao Estado. Na "Puchase Tax" os produtos foram. distribuídos em trinta e três grupos e as aliquotas atualmente vigentes são de $5 \%, 15 \%, 30 \%$ e $60 \%$. No Grupo 19 , por exemplo, os rádios, televisões e os discos de vitrolas estão tributados na base de $60 \%$. Mas os pianos, mesmo os de brinquedo, estão isentos. No grupo 20 , os brinquedos e os artigos de esporte estão tributados na base de 30\%, mas isentaram-se os barcos mesmo luxuosos destinados ao desporte aquático. Enquanto no grupo 27 os automóveis sujeitam-se a uma aliquota de $60 \%$, as carruagens puxadas por animais estão tributadas na base de $30 \%$. As jóias no grupo 4 e os produtos farmacêuticos no grupo 33 estão tributados na mesma base de $30 \%(20)$. Vê-se por ai que a distribuição seletiva da carga fiscal está longe de ser atingida. Nem é para menos. Como seria possivel com apenas quatro faixas de incidência atender ao multifário aspecto da consumação de produtos tendo em vista o nivel de vida da população e as suas necessidades vitais e culturais? A gradação se fêz, mas "grosso modo". O mesmo acontece com a "Taxe sur la Valeur Ajoutés" na França, onde, de acôrdo com a última reforma fiscal levada a efeito em 1959 a alíquota normal passou a ser de $20 \%$, instituindo-se as aliquotas de $23 \%$ e $25 \%$ para certos produtos conisderados de luxo e as aliquotas reduzidas de $6 \%$ e $10 \%$ para outros produtos considerados de necessidade corrente. Mas a distribuição seletiva da carga fiscal demandaria pelo menos umas mil aliquotas como ocorria na Rússia em 1930. A lição que nos dão assim a Inglaterra e a França é extremamente valiosa. O impôsto de consumo e de vendas e consignações, embora em condições de atender a certos aspectos básicos de justiça distributiva são, antes de tudo, eficazes instrumentos de imposição fiscal. Sua ação permanecerá sempre contingenciada pelos dois objetivos perseguidos: proporcionar renda ao Estado e estabelecer uma certa graduação na distribuição da carga fiscal. Foi encarando com objetividade êste duplo aspecto do impôsto no mundo moderno que Henry Laufenburger (21) pôde afirmar: "mas na medida em que, ao abrigo do intervencionismo estrutural ou conjuntural, o impôsto desempenha a função de coletor neutro dos meios necessários para assegurar o funcionamento dos serviços públicos no sentido largo da palavra, êle pode, senão responder em tôdas as suas manifestações ao conceito de capacidade, pelo menos se. apıoximar dêle".

Foi Adam Smith (22) quem estabeleceu as quatro regras clássicas a que deviam se submeter os governos na criação de impostos. "Antes de entrar no exame das taxas particulares - dizia êle - necessário se faz estabelecer as quatro máximas sôbre os impostos em geral".

(20) Dados extraídos de "Notice by The Commissioners of Customs and Excise" outubro de 1958, Notice n. 78).

(21) Henry LAufenburger, Théorie Économique et Psychologique des Finances Publiques, Paris, 1956, p. 149).

22) Арам Sмrтн, Richesse des Nations, (livro V, Capitulo II). 
19) "Os sujeitos devem contribuir para as despesas do govêrno tanto quanto possivel, em razão de suas faculdades respectivas, isto é, na proporção da renda que usufruem sob a proteção do Estado". Regra da igualdade ou da justiça do impôsto.

2.) "A taxa imposta a cada cidadão deve ser certa e não arbitrária. 0 tempo do pagamento, a maneira de pagar, a quota a pagar, tudo deve ser claro e preciso para o contribuinte e para todos, sem o que o contribuinte ficaria mais ou menos à mercê do coletor". Regra da certeza.

3:) "Tôda contribuição deve ser cobrada na época própria e da maneira que pareça ser a mais conveniente para o contribuinte". Regra da Comodiilade.

4\%) "Tôda contribuição deve ser estabelecida da maneira a retirar dos bolsos do povo o menos possivel". Regra da economia.

Como observa Maurice Duverger (23) os economistas modernos não renegam os principios clássicos das imposições tributárias, mas juntam-lhe um principio novo: o do intervencionismo fiscal. Ao conflito tradicional entre a igualdade e o rendimento, acrescentam-se, agora, conflitos novos: entre $o$ rendimento $e$ o intervencionismo e entre o intervencionismo e a igualdade.

O problema não é realmente novo. Vicenzo Tangorra, que pode ser considerado um financista clássico, já admitia que os privilégios fiscais decorrentes de princípios sociais se justificavam plenamente devido à evolução do conceito político-jurídico d Estado. (24) Mas foi sem dúvida Mainard Keynes (25) quem, considerando a politica fiscal como a ação do Estado em conceito de fator compensador, abrit novas perspectivas para a discussão entre os que defendem ou atacam o neutralismo e o intervencionismo fiscais. Para Alain Barrère (26), o que Keynes propõe "é uma fiscalidade suscetivel de encorajar o desenvolvimento do consumo e de penalizar a constituição de uma poupança excessiva, de modo a garantir, na economia interna, uma situação permanente de pleno emprêgo.

Mas o intervencionismo fiscal - se considerarmos a fiscalidade como uma das maiores fôrças de coação do Estado contra os cidadãos - levado às suas últimas consequiências, levará, inapelàvelmente, à ditadura política. Acresce que, como vimos, dada a peculiaridade de nosso sistema fiscal, com a divisão de competência estabelecida pela Constituição, dificilmente poderiamos fazer do impôsto de consumo um instrumento de política econômica do govêrno. O papel corretor, tanto quanto possivel, deverá caber ao impôsto de renda. Isto aliás, é o que parece acontecer em todos os

(23) Maurice Duverger, Institutions Financières, Paris, 1957, pp. 107 e segs.).

(24) Vicenzo Tangorra, Trattado di Scienza della Finanza, Milano, 1915, p. 798).

(25) Mainard Keynes, General Theory, p. 220).

(26) Alain BarRère, Théorie Êconomique et Impulsion Keynesienne, Paris, 1952. 
paises ocidentais, conforme afirma Henry Laufenburger. (27) «a combinação do impôsto direto e do impôsto indireto tem por objetivo, nos países démocráticos, conciliar a necessidade da justiça fiscal com a preocupação do rendimento fiscal".

A nova estrutura dada à discriminação dos produtos sujeitos ao impôsto de consumo e a multiplicidade desarrazoada das aliquotas de incidência têm sido causa dos maiores tropeços à boa aplicação da lei. A vinculação da nomenclatura do impôsto de consumo indiretamente à nomenclatura de mercadorias de Bruxelas não pode, realmente, senão aumentar as dôres de cabeça e as preocupações de nossos industriais trazendo desassossêgo e inquietação para quem se dedica a qualquer ramo de atividade produtiva no país. Já agora, a classificação de um produto comporta não só discussões de caráter interno, mas também de interpretação da nomenclatura de mercadorias de Bruxelas, o que é, sem nenhuma dúvida, um exagêro.

Outro objetivo declaradamente perseguido pelos autores da reforma foi o de dar ao govêrno, com a nova nomenclatura dos produtos tributados, uma massa razoável de dados estatísticos para orientar-lhe a ação em matéria de politica fiscal. Ora, é impressionante que se faça de uma lei de impostos um instrumento de coleta de dados estatísticos, quando para tal fim há órgãos específicos como o Instituto Brasileiro de Geografia e Estatística. $\mathrm{Na}$ verdade, a discriminação dos produtos, como foi estabelecida na lei, não representou senão um passo para trás na técnica tributária pretendendo conciliar a generalização do tributo com o regime de discriminação constante do Regulamento de 1938. Dêste apêgo ao passado ou da incompreensão das implicações que haveria de acarretar a generalização do tributo, resultou que a nova lei do impôsto de consumo se transformou num instrumento pesado, hibrido, de manejo difícil e um estôrvo a mais para aquêles que se dedicam às atividades produtivas no país. Citaremos três exemplos para demonstrar a confusão reinante na matéria.

\section{O caso dos colchões}

A Alinea IV do Regulamento do Impôsto de Consumo tributa os artefatos de têxtil e, portanto, no entender da Diretoria das Rendas Internas, os artefatos de teciús. A aliquota ali prevista é de $10 \%$. Por sua vez, a Alinea XIV, inciso 3, tributa os artefatos de metal na base de $6 \%$. A Diretoria das Rendas Internas, com base no art. 4\%, letra "b" das Normas Gerais do Regulamento do Impôsto de Consumo, entendeu que "ao colchão de mola o que the confere caráter essencial é a mola". Donde decorre que o colchão de mola está tributado com $6 \%$, o de borracha com $7 \%$ e os de matéria plástica (se a matéria plástica fôr o conteúdo do colchão), com $8 \%$; mas os de matéria plastica ou de tecido tendo como conteúdo pena, crina, paina ou capim, estâo isentos. 


\section{O caso dos produtos quimicos}

Determinada firma consultou à D.R.I. qual a classificação dos produtos que desejava importar, adiantando que os mesmos se destinariam exclusivamente à composição de produtos alimentares. Os produtos eram os seguintes: e) vanilina; $b$ ) lecitinas; c) óleos: 1 - de flor de laranja; 2 - de laranja deterpenando; 3 - de laranja amargo; e 4 - de laranja dôce; d) ácido cítrico.

A D.R.I., não sabendo ela mesma como responder, consultou ao Labo ratório Nacional de Análises indagando se os produtos descritos seriam.

a) óleos essenciais simples ou combinados, naturais ou artificiais, ou produtus quimicos aromáticos que constituem matéria prima básica para composição de perfumes?;

b) ou complementos alimentares de que fala o inciso 3 da Alinea I?;

c) ou estarian classificados na Alinea XIII - Produtos das Indústrias Quimicas, como :

10) produtos quínicos orgânicos ou inorgânicos produzidos industrialmente ou,

29) preparaçes nâo especificadas?

Não sei qual teria sido a resposta do Laboratório Nacional de Análises. Mas, sem levar em conta a confusão da D.R.I., admitindo que os produtos em questão pudessem ser considerados como "sopas e caldos" (Alínea I, inciso 3) a situação scria a seguinte: se se tratasse de óleos essenciais constituindo matéria prima básica para composição de perfumes, o impôsto seria de $50 \%$. Se se tratasse de produtos quimicos orgânicos ou inorgânicos produzidos industrialmente, o impôsto seria de $2 \%$. Se, porém, os produtos fôsser considerados como "preparações não especificadas" o impôsto seria de $6 \%$.

\section{caso dos tubos}

A Alinea XIV, inciso 1, tributa com $2 \%$, “os tubos, canos, barras ôcas e outras formas semelhantes, obtidas por laminação, forjamento, estiragem, trefilação, centrifugação, fundição ou estrusão de qualquer metal". Sucede que há emprêsas que compram as lâminas de metal já de tamanho certo e as soldam, fabricando o que se chama "tubo costurado". Pois bem, tais tubos passam a ser "artefatos de metal" não especificados tributados com $6 \%$, no inciso 3. Da mesma maneira, estão tributados na base de $6 \%$ as conexões, luvas, tês e demais acessórios dos tubos, quando de metal. Porque em se tratando de tubos ou conexões de cimento, o impôsto será sempre de $2 \%$. Mas se se tratar de tubos de cerâmica, o impôsto será de $5 \%$.

Os "casos" poderiam ser multiplicados aos milhares. Os corriqueiros lápis, por exemplo, estão classificados na lei do impôsto de consumo como 
"produtos da indústria quimica" (preparações e composições para escrever), enquanto que as canetas-tinteiro e as lapiseiras foram contempladas com uma Alinea especial. Uima ferramenta composta de mais de uma peça, se vendida completa, está tributada na base de $2 \%$, mas se as peças forem vendidas separadamente e, o impôsto será de $6 \%$ quando de metal, de $7 \%$ quando de borracha ou de $8 \%$ quando de matéria plástica. Os óculos estão tributados com $6 \%$. Mas as armações para óculos de matéria plástica, se vendidas separadamente, ficarão gravadas com o impôsto de $8 \%$. Só na Alínea I (Produtos Alimentares Industrializados), encontramos cinco aliquotas de incidência. Que critério de politica econômica teria presidido a tal disparidade de taxas? Se algum critério houve, seu êxito estaria irremediàvelmente curnprometido pela complexidade que acarretou ao funcionamento do sistema. A intranqüilidade do contribuinte, sujeito muitas vêzes a multas imerecidas, é fator negativo da produtividade fiscal. Não tenho nenhuma simpatia pelo sonegador de impostos, mas não posso admitir como legítima ou razoável a inulta decorrente de futricas da lei. Da politica fiscal, tem-se que exigir um minimo de coerência com a filosofia politica que informa as instituiçōes estatais. Num regime capitalista, onde a produção decorre da iniciativa privada, os homens de emprêsa, as classes produtores são a alavanca do progresso. Se não merecerem por isso nenhum privilégio especial - o que é evidente - devem, contudo, ser incentivados a produzir cada vez mais e melhor. Neste sentido, uma politica fiscal bem orientada e menos opressiva poderia contribuir enormemente para o progresso material do pais.

A questão da incidência cumulativa do impôsto de consumo sôbre os produtos intermediários da fabricação parecer ter sido posta pela primeira vez no tabuleiro das discussões pela comissão designada pelo Sr. Ministro da Fazenda para dar parecer sôbre o anteprojeto de Código Tributário, elaborado pelo Dr. Rubens Gomes de Souza. (27) Realmente, embora no original do anteprojeto nada conste a respeito, o art. $26, \S 1^{\circ}$ do substitutivo apresentadc pela referida comissão estabelece : "o impôsto incide uma única vez sôbre os produtos industrializados destinados ao consumo interno do país, assegurado ao produtor final, inclusive beneficiadores e transformadores, a dedução do impôsto relativo às matérias primas e produtos intermediários empregados na respectiva indústria".

Vè-se, assim, que a citada comissão, que era composta dos Senhores Tito Rezende (Presidente), Carlos da Rocha Guimarâes, Eduardo Lopes Rodrigues, Jaime. Péricles e Gilberto de Ulchôa Canto escolheu o sistema da dedutibilidade ou do pagamento fracionado para obviar as distorsões resultantes da cumulatividade do impôsto. E' bem possivel que a escolha tenha resultado da novidade introduzida no sistema fiscal francês pelo Decreto de 9 de dezembro de 1948 e em virtude da qual os contribuintes foram autorizados a deduzir do impôsto a pagar o impôsto que havia onerado a matéria prima destinada à fabricação do produto final. Mas os motivos que induziram o govêrno francês a estabelecer o sistema que lá se chama de

(28) Codificação do Direito Tributário, Publicação $\mathrm{n}^{\circ} 4$ do Instituto Brasileiro de Direito Financeiro. 
"paiements fractionnés" foram bem outros. Desde 1936, quando se instituira a "tax à la production" - equivalente ao nosso impôsto de consumo o impôst. deixara de ser cumulativo. Mas àquela época, isto é, em 1936 , para evitar o fenômeno da incidência cumulativa ou em cascata, adotara-se o processo da transíerência da mercadoria com suspensão do impôsto, isto é, os produtores fiscais, os fabricantes, recebiam o produto, desde que destinado à fabricação, transformação ou beneficiamento, livre do impôsto. E êste só seria pago qquando o produto acabado fôsse vendido a um não contribuinte ou ao consumidor. Evidentemente, o sistema de transferência com suspensão d’ impôsto déferia para uma data mais afastada a percepção do tributo, de vez que êste só seria pago após completado todo o ciclo de fabricação. Lutando o tesouro francês com dificuldades de numerário, imaginou-se que a melhor solução seria estabelecer o sistema de pagamento fracionado. Assin, cada iabricante, ao transferir a matéria prima para outro fabricante faturava o impôsto à parte e o recolhia ao Tesouro. Por sua vez, o fabricante que havia recebido o produto onerado com o impôsto, levava êste último a set: crédito, pagando, posteriormente, a diferença decorrente do seu prêço de venda (29). Vê-se, pois, que o sistema de pagamento fracionado instituido pelo govêrno francês em 1948 e que serviu de modêlo ao legislador brasileiro näo foi imaginado para corrigir as distorsões decorrentes da incidència cumulativa, mas para obviar dificuldades de tesouraria. Mas mesmo na França, o sistema deu origem a tantas dificuldades e a tantas complicações que se pode assegurar com certeza o retôrno ao sistema de transferência com suspensão do impôsto.

Antes da criaçĩo do sistefa de pagamento fracionado, eram duas as soluçôes clássicas adotadas para impedir o fenômeno da incidência cumulativa dn impôsto: $1^{\text {a }}$ - a exoneração das matérias primas destinadas à confecçăo do produto final e $2^{a}$ - a transferência com suspensão do impôsto.

A dificuldade inerente à primeira solução é que nem sempre é fácil conceituar o que seja matéria prima. Exemplo flagrante desta dificuldade nos detı o Regulamento do Impôsto de Consumo de 1945, que, embora isentando do tributo $\mathrm{cm}$ quase tôdas as Alineas, aquilo que pudesse ser considerado matéria prinı, não conseguiu eliminar inteiramente o problema. A questão tornou-se mais aguda com o acelerado processo de industrialização do pais. Indústrias bastante complexas, empregando na confecção de seus produtos já não apenas matérias primas no sentido restrito da palavra, mas produtos acabados e sujeitos por sua vez ao impôsto de consumo, começararn a compreender o impacto que representava para o custo de produção, a incidência cumulativa do impôsto. As indústrias mais afetadas eram, sem dúvida, a automobilística e a de aparelhos elétricos domésticos. A sobrecarga do impôsto forçava a integração vertical das emprêsas, contrariando o desenvolvimento clássico sobretudo da indústria automobilística que, em quase todos os paises, se caracteriza pela dispersão das emprêsas, cada uma se especializando em determinado ramo da produção. Não se

(29) Sôbre o assunto, ver "Cours de Taxes sur le Chiffre d'Affaires", de PIERRE. Crroux, Paris, 1958, p. 7; e Finances et Fiscalité de André Turq., p. 79. 
pode pegar aos autores da reforma de 1958 o mérito de haver agitado o problema e mesmo lorçado uma solução, embora esta não tenha atingido plenamente os seus objetivos.

Mas não é apenas no setor das indústrias complexas que a distorsão provocada pelo sistema de tributação cumulativa se faz sentir de maneira funesta. Mesmo nas indústrias simples, êle deturpa a concorrência comercial, penalisando as emprêsas cujo circuito de produção seja mais longo do que o de suas congêneres $\left(a^{2} 0\right)$. Imaginemos, por exemplo, três fábricas que consumam cada uma, anualmente, uma tonelada de matéria prima, submetidas a um regime de tributaçâio em cascata puro. Suponhamos, ainda, que o preço da matéria prima seja de $\operatorname{Cr} \$ 50.000,00$ a tonelada e o impôsto de $10 \%$. A primeira fábrica, comprando a matéria prima diretamente do produtor, desembolsará Cr $\$ 55.000,00$ (50.000 mais 5.000); a segunda, comprando-a do primeiro intermediárı, pagará $\operatorname{Cr} \$ 60.500,00$ (55.000 mais 5.500); e a terceira, adquirindin $-a$ de um segundo intermediário, paragará $\operatorname{Cr} \$ 66.500,00$ $(60.500$ mais 6.050$)$. No cálculo acima, eliminamos, propositadamente, o lucro dos intermediários para ressaltar exclusivamente o papel distorsivo representado pelo sisienna de tributação em cascata. O terceiro fabricante mesmo se a produtividade do trabalho fôr idêntica em ambas as emprêsas, para concorrer no mercado com o primeiro, terá que se contentar com um lucro a menos de $\operatorname{Cr} \$ 11 \cdot 550,00$. Em todo o mundo, o problema tem sido debatido e estudado. A Liga Européia de Cooperação Econômica (31). estudando a questão da criação do Mercado Comum Europeu, afirma que o sistema de tributação cumulativa cria verdadeiras barreiras fiscais entre os países, tornando de valor relativo a sup.essão das barreiras aduaneiras. Ressalta, ainda, a mesma publicação que três paises do mercado comum (Alemanha, Holanda e Luxemburgo) aplicam sistemas de impostos cumulativos nais ou menos puros. Dois, (Bélgica e Itália), aplicam sistemas de impostos cumulativos para uma parte de seus produtos e um sistema de "taxa única" para a outra parte. E finalmente, a França possui um sistema de impôsto não cumulativo quase puro. A matéria nos interessa de perto, já que ensaiamos a criaçăo de um mercado comum latino-americano. Dificilmente, porém, conseguriamos implantar um sistema de incidência não cumulativa puro como o da França. A discriminação de rendas estabelecida pela Constituição é um óbice irremovivel e tanto mais sério quanto não se pode vislumbrar - considerada a nossa realidade politica de Estado Federativo - inelhor solução do yue a encontrada pelos constituintes de 1946. Devemos nos contentar com um sistema misto, mas para isto devemos eliminar inteiramente do impôsto de consumo, o fenômeno da incidência em

(30) "Com efeito, as percepções efetuadas durante os diferentes estágios de fabricação se ajuntam umas às outras, de tal maneira que o pêso do impôsto será tanto maior quanto maior for a cadeia de empresas de que saiu o produto. Esta afirmação está subordinada à condição geralmente verificada, de que os diversos estágios de fabricação são espaçados de maneira regular no curso da formação do valor do produto. Poder-se-ia, porém, imaginar espaçamentos suficientemente irregulares para que um circuito longo seja menos taxado do que um circuito curto". (Maurice Laure, Traité, p. 85).

1959, p. 10 . 
cascata. Porque, na realidade, a reforma de 1958 não conseguiu êsse desiderato. Assim é que o fabricante que importar diretamente a matéria prima ou comprá-la diretamente do produtor poderá levar a seu crédito o impôsto de consumo que a gravou. O mesmo, porém, não acontece com o fabricante que tenha adquirido a matéria prima de um comerciante grossista. Não sendo o comerciante grossista contribuinte do impôsto de consumo, não poderá êle faturar o impôsto em separado, decorrendo daí uma situação de inferioridade do seguudic fabricante com relação ao primeiro. Exemplifiquemos: dois fabricantes de artefatos de cimento (o cimento está gravado com $10 \%$ na lei do imfosto de consumo) consomem cada um, duas toneladas de cimento por ano. $\mathrm{O}$ primeiro compra o cimento diretamente à fábrica produtora que the tatura o produto por $\operatorname{Cr} \$ 240.000,00$ e mais o impôsto de consumo na importância de Cr\$24.000,00, perfazendo o total de Cr $\$ 264.000,00$. Como o impôsto de consumo the foi faturado em separado, êle levará o seu crédito aquêles $\mathrm{Cr} \$ 24.000,00$. O segundo, que compra o cimentc a um comerciante grossista, não podendo se beneficiar da dedução, ficará, evidentemente, prejudicado na concorrência comercial. Se levarmos em consideraşão que a maioria dos nossos fabricantes de artefatos de cimento, de ferro ou mesmo de produtos químicos e farmacêuticos adquirem a matéria prima através de intermediários, verificaremos que o sistema de pagamento fracionado do impôsto entre nós não resolveu, em absoluto, o problema da incidência cumulativa.

A outra solução clássica para se evitar o fenômeno da incidência do impôsto em cascata consıste em permitir aos fabricantes a remessa reciproca dos produtos destinados a fabricação, transformação ou beneficiamento, com suspensão do impôsto. Mas esta questão será abordada no final de nosso trabalho.

\section{LINHAS GERAIS DA REFORMA PROPOSTA}

As aliquotas atualmente em vigor na lei do impôsto de consumo são as seguintes :

2\% -.. para os produtos das Alineas I, inciso 1; II - incisos 1, 2 e 3; IV, inciso 1; VI, inciso 1; VII, inciso 1; VIII, inciso 1 ; X, inciso 1 ; XIII, incisos 1 e 2: XIV, incisos 1 e 2: XV. incisos 1, 2, 3, 4 e 5: XVI, inciso 8; XVII, inciso 1 ;

$3 \%$ - para os prociutos das Alineas I, incisos 2, 3 e 4; II, inciso 4; IX. inciso 1; XIII, inciso 3 e 7; XVI, inciso 7:

$4 \%$ - para os produtos das Alineas I, incisos 5 e 6; II, incisos 5,6 e 7 ; IV, inciso 2; VIII, inciso 2: XV, inciso 6;

$5 \%$ para os produtos das Alineas I, incisos 7, 8, 9, 10 e 11; VIII, inciso 3: $\mathrm{X}$. inciso 2: XI, inciso 1; XII, inciso 1; XV, inciso 10; XVI, incisos 2 e 6; XVIII, inciso 2;

$6 \%$ - para os produtos das Alíneas III, inciso 1; IV, incisos 3 e 4; VIII, inciso 4; IX, incisos 2 e 7; X, incisos 3,4 e 5; XI, incisos 2, 3, 4 e 5; XIII, 
incisos 4, 5 e 6; XIV, incisos 7, 8 e 9; XVI, inciso 4; XVII, incisos 3 e 4; XVIII, incisos $1,2,3,4,5,6$ e 7 ;

$7 \%$ - para os produtos das Alíneas VII, incisos 2, 3 e 4; IX, incisos 3, 4 e 5; XIII, incisos $\delta$ e 9; XIV, inciso 4; XXI, incisos 1 e 2; XXVI, incisos 2 e 3 ;

$8 \%$ - para os produtos das Alineas VI, inciso 2; IX, inciso 6: XII, inciso 2; XVIII, inciso 8; XIX, incisos 1, 2, 3 e 4; XXI, incisos 3, 4 e 5;

$10 \%$ - para os produtos das Alineas IV, incisos, 6, 7, 8, 9, 10 e 11; X, inciso 6; XVI, incisos 1, letra "a" e 5; XIX, inciso 5; XX, inciso 1;

$12 \%$ - para os produtos da Alínea V;

$15 \%$ - para os produtos das Alineas XVI, inciso 1, letra "b"; XX. inciso 2: XXI, inciso 6:

$16 \%$ - para os produtos da Alinea XXVI, inciso 1;

$20 \%$ - para os produtos das Alineas I, inciso 12; III, inciso 2; VI, inciso 3; XVI, inciso 1, letra "c"; XX, inciso 3; XXI, inciso 7;

$30 \%$ - para os produtos das Alineas XX, inciso 4; XXI, inciso 8;

$35 \%$-- para os produtos da Alinea III, inciso 3;

$50 \%$ - para os produtos da Alinea III, inciso 4;

$55 \%$ - para os produtos da Alinea XXIV, inciso 2, último item. cífico.

Os fósforos e a nnaioria das bebidas estão sujeitos ao impôsto espe-

A multiplicidade de aliquotas não é, por si só, um mal. Mas uma coisa é absolutamente certa : ela não se coaduna com a difusão ou com a generalização do tributo. $\mathrm{E}$ isto porque o legislador, por mais minucioso que pretenda ser, nấo poderá designar, nominalmente, todos os produtos tributados. Terá, pois, que recorrer a expressões vagas, como as que constam de quase tôdas as Alineas: "tôda e qualquer máquina ou aparelho não especificado, nem incluído em outra parte", "quaisquer artefatos ou confecções de têxtil não especificados nem compreendidos em outra parte", etc. Dai decorrem verdadeiros absurdos, situações vexatórias e injustificáveis. Faz-se, pois, mister reduzir o número de aliquotas, sem desprezar de todo o critério de justiça na distribuição da carg̣a fiscal. Mas forçoso é confessar que o impôsto de consumo é, antes de tudo, um impôsto de alta rentabilidade fiscal e que é justamente isto que justifica a sua permanência na receita tributária de quase todos os países democráticus. O retôrno ao sistema de tributação limitada ou restrita como ocorria no Regulamento de 1938 ou mesmo no Decreto-lei n 7.404 de 22 de março de 1945 parece-me a esta altura inviável. Uma vez alargado o âmbito de tributação, dificilmente o govêrno haveria de concordar em restringi-lo. Isto seria não só inédito, mas contrário às crescentes necessidades orçamentárias da União. E não se poderia esperar nem do diploma de 1938 nem do de 1945 , um rendimento igual ao da lei atual sem uma elevação sufocante e intolerável das aliquotas. 
Encarando, pois, friamente, o problema, veremos que a única solução para acabar com o mal-estar e as queixas generalizadas da indústria estará em se dar uma nova estrutura à lei do impôsto de consumo, aproveitando a experiência de jutros países. Na Inglaterra, o impôsto é pago pelo comerciante grossista, transitando a mercadoria do fabricante para o grossista ou ainda de fabricante para fabricante ou de grossista para grossista, com suspensão do impôsto (32). O impôsto só é pago pelo fabricante quando êste vende diretamente o produto ao consumidor ou a um comerciante varejista. Na França, onde o sistema de pagamento fracionado tem sido fonte das maiores complexidades, pretenderse retornar ao sistema de transferência com suspensão do impôsto, incluindo-se, para isto, grossistas e fabricantes, na categoria de produtores fiscais.

Vou dar a palavra a Maurice Lauré que, tendo sido um dos criadores. do sistema de pagamento fracionado do impôsto na França, é hoje o maior defensor do retôrno ao sistema suspensivo. "O retôrno ao sistema suspensivo do impôsto - - diz êle - é a chave de tôdas as sugestões que iremos fazer". E mais adiante :

"No sistema de pagamento fracionado, cada produtor" fatura e cobra o imposto sôbre tôdas as suas vendas, sem se incomodar corı a posição fiscal de seus clientes. Desde que êstes sejam consumidores finais ou emprêsas não sujeitas ao impôsto, êste se acha definitivamente pago. Mas se os clientes forem também "produtores tiscais" (contribuinteș), o efeito da tributação é ràpidamente anulado, de vez que êsses produtores deduzem do impôsto a pagar, aquêle que lhes foi faturado quando de suas compras. $E^{\prime}$ por isso que, no sistema de pagamento fracionado, pouco interessa ao vendedor conhecer a situação fiscal de seus clientes.

No sistema de transferência com suspensão do impôsto, ao contrário é recessário que cada contribuinte opere uma distinção entre as vendas feitas a "não produtores" e as vendas feitas a "produtores".

Para as rendas a "não produtores" (quer sejam consumidores finais ou emprêsas isentas), o impôsto é faturado e cobrado, de tal sorte que fica imediatamente incorporado ao ativo do Tesouro. Mas quando as vendas são feitas a "produtores fiscais" (contribuintes), o impôsto não será cobrado nem faturado, ficando o comprador obrigado a fornecer ao vendedor um atestado de sua qualidade.

A cbrigação de pagar e liquidar o impôsto pertence, sempre, ao último "produtor fiscal" da cadeia.

Pode acontecer, todavia, que um "produtor fiscal" realize compras com suspensão do impôsto e depois utilize o produto comprado na fabricação de um produto não tributado ou se utilize dêle para seu gasto pessoal. Neste caso, o referido "produtor" devera pagar o impôsto como se tivesse feito uma venda a um não.

(32) Lucien Mehl, ob. cit., Tomo II, p. 611. 
contribuinte. A recepção de uma mercadoria com suspensão de impôsto torna, pois, o recebedor responsável pelo pagamento do tributo. E êle só se livrará desta responsabilidade pagando o impôsto ou provando que vendeu o produto a um outro "produtor". (33)

Nisto consiste, em linhas gerais, o sistema de transferência com suspensão de impôsto e que nós consideramos a solução lógica para remediar os inúmeros entraves que a nova lei do impôsto de consumo criou para os industriais.

Uma vez estabelecida uma aliquota geral para todo produto industrializado, manufaturado ou cmifatura in aliquotas, duas abaixo e duas acima da aliquota geral para estabelecer uma certa gradaçã na distribuição da carga fiscal e exonerar-se-iam os produtos que, nos têrmos da Constituição, a lei considerasse o mínimo indispensável à habitaçãc, vestuário, alimentação e tratamento médico das pessoas de restrita capacidade econômica. Essas deveriam ser as únicas isenções consagradas no texto da lei, eliminando-se tôdas as demais vigorantes até hoje. As dezesseis aliquotas constantes do regulamento atual seriam, pois, substituidas por cinco.

A vantagem principal de estabelecer-se uma aliquota geral é que isto permitirá discriminar de maneira muito mais lógica e racional os produtos sujeitos às aliquotas majoradas ou reduzidas. Com isso, desapareceriam, pràticamente, tôdas as confusões decorrentes do critério da classificação dos produtos adotado pelo art. 40 das Normas Gerais do Regulamento vigente.

O contrôle da arrecadação se faria fàcilmente. Poderíamos imaginar o seguinte sistema: a repartição do domicilio fiscal do contribuinte (fabricante ou grossista) fornecer-lhe-ia um atestado (ou tantos quantos fôssem pedidos) de que o mesmo poderia receber produtos com suspensão do impôsto. Estes certificados ou suas cópias fotostáticas seriam remetidos pelo interessado aos fabricantes ou comerciantes grossistas de produtos tributados com os quais mantivesse relações comerciais e seriam válidos por quatro meses. Uma vez de posse dêste certificado, ficava o vencedor habilitado a remeter ao seu cliente qualquer produto com suspensão do impôsto, ficando automàticamente, desonerado de qualquer responsabilidade quanto ao pagamento do tributo. Esta responsabilidade passaria a ser exclusiva do recebedor da mercadoria.

Para a renovação do certificado, a repartição teria apenas que verificar se o contribuinte vinha pagando quinzenalmente ou mensalmente o impôsto, admitindo-se uma tolerância de três meses.

Como já dissemos, o sistema implica em transferir para o comerciante grossista, definidı como o que revende a outros comerciantes, a obrigação de pagar o tributo. Realmente, o fabricante só o pagará quando vender a um consumidor ou a um não contribuinte. Mesmo na Inglaterra, porém, onde

(33) Maurice Lauré, Au Secours de la T.V.S., pp. 89-90. 
- sistema é adotado, entendeu-se de bom aviso abrir algumas exceções como para o caso dos automóveis, em que o impôsto é pago pelo fabricante, nada mais se exigindo do revendedor. Estas questões teriam que ser estudadas cort mais vagar.

Aquêles que vendessem produtos com suspensão do impôsto teriam Notas Fiscais especiais para isto e enviariam, até o término da primeira quinzena do mês subseqüente à repartição do domicílio do comprador, uma via das Notas Fiscais emitidas no mês anterior. Cada contribuinte seria cadastrado na repartiçãc de seu domicilio, com um número de inscrição e teria uma pasta especial onde se contivessem todos os documentos referentes ao mesmo, inclusive as vias das Notas Fiscais acima referidas. Por intermédio delas, a repartiçâo controlaria a quantidade e qualidade dos produtos recebidos com suspensão do impôsto. Evidentemente, teríamos que estabelecer penas severas, até mesmo de prisão, para aquêles que falsificassem os atestados fornecidos pela repartição e que assim passassem a receber, fraudulentamente, produtos com suspensão do impôsto.

Teriamos qui: eliminar a tributação especial hoje vigente para café torrado. móveis e calçados, acabando-se com a exigência da numeração para êstes últimos. A selagem por estampilhas deveria ficar adstrita ao fumo e fósforos, assim mesmo se não se conseguisse uma solução que os enquadrasse no sistema geral.

Acabarianos, também, com o sêlo de autenticação e criariamos um regime jurídico especial para os produtos estrangeiros, mas apenas no que diz respeito às medidas de contrôle. Seguindo a regra geral, o impôsto deixaria de ser pago na Alfândega, para sê-lo pelo grossista, quando da venda do produto ao consumidor.

Em qualquer hipútese, as aliquotas deveriam ser reduzidas de $25 \%$ quando o impôsto fôsse pago pelo comerciante grossista, de modo a corrigir em parte, o desajuste decorrente da diferença entre os preços de venda do fabricante do grossista.

Para eliminar, definitivamente, o fenômeno da incidência cumulativa do impôsto, a lei disporia que não se consideraria consumidor o industrial de produtos tributados que adquirisse matérias primas ou quaisquer produtos destinados à confecçâo ou embalagem de seus produtos ou ainda máquinas ou equipamentos mecânicos destinados à aplicação em sua indústria.

A discriminação mmuciosa dos produtos nas Notas Fiscais - que a lei atual consagrou de maneira até aberrante do bom senso - passaria a ter um valor bastante relativo. Isto ensejaria uma revisão adequada do atual dispositivn sôhre a matéria.

Nos caso: de exportação para o exterior com isenção do impôsto, exigir-se-iam, simplesmente, Notas Fiscais especiais. Eliminar-se-iam todos os contrôles atualmente em vigor, obrigando-se, porém, o exportador, depois de um certo prazo - mais ou menos cento e vinte dias - a manter consigo, para exibir, quando exigidos pela fiscalização, os documentos comprobatórios da exportação

Uma vez superadas as dificuldades de ordem técnica - o que nos parece extremamente fácil - duas objeções se poderiam fazer ao novo sistema : 
a) haveria um reiardamento na percepção do tributo, de vez que êste passaria a ser exigido após a venda efetuada pelo grossista e não pelo fabricante, como no regime atual:

b) haveria uma infringência ao dispositivo constitucional que estabelece a discriminação de rendas pelo fato de confundir-se, no sistema proposto, o impôsto de consumo com o de vendas e consignações.

Nenhuma das objeçũes é realmente séria.

$\mathrm{Na}$ verdade, a percepção do tributo seria um pouco retardada.

Mas, pressupondo que o grossista - a não ser em épocas anormais de conjuntura inflacionária - não tem nenhum interêsse em engrossar os seus estoques, pode-se admitir como razoável um espaçamento de apenas um ou dois meses entre a venda efetuada pelo fabricante e a efetuada pelo grossista.

Com referência à inconstitucionalidade do sistema, a objeção é ainda menos consistente.

Impôsto de consumo e impôsto sôbre vendas e consignaçôes são ambos impostos sôbre a despesa e, portanto, impostos "sôbre o consumo" ou "de consumo".

Rubens Gomes de Souza, estudando a natureza do impôsto de consumo no Brasil diz :

"Na nossa opinião, seguindo, aliás, a expressa por Alde Sampaio, não há diferença entre os dois impostos (de consumo e de vendas e consignações), que têm a mesma base econômica - a renda geral da nação o mesmo fato gerador - a venda dos artigos tributados - ... e que são pagos pelo mesmo contribuinte legal. As únicas diferenças estão na modalidade fiscal ou seja, na maneira de se calcular o impôsto e no processo de arrecadação... Essas diferenças, entretanto, como é fácil de ver, são meramente formais e em nada alteram a identidade substancial dos dois tributos... (34)

Se quizéssemos definir hoje o impôsto de consumo no Brasil, poderiamos dizer que " " o impôsto sôbre a despesa (ou sôbre a renda consumida) cobrado de acôrdo com o que preceitua o Decreto $n^{\circ} 45.422$ de 12 de fevereiro de 1959" ou ainda "que o impôsto sôbre a despesa cobrado de acôrdo com o Decretc n 45.422 é o impôsto de consumo". E não poderíamos sair dessa definição tautológica: porque ela decorre do nominalismo adotado pela Constituição brasilerra na discriminação de rendas, isto é, do fato de a Constituição designar por seus nomes os impostos pertencentes às diversas entidades politicas.

Assim, bastará que a lei regulamente de maneira diferente a cobrança do impôsto de consumo para que o seu conceito se altere. E não se poderá jamais invocar a inconstitucionalidade do tributo se êle se mantiver como um típico impôsto incidente sôbre o consumo de mercadorias. Ora, na inovação que propomos, o impôsto permanece como um tipico impôsto sôbre o consumo de mercadorias, sendo, pois, descabida, qualquer alegação de inconstitucionalidade.

(34) Rubens Gomes de Souza, Estudos de Direito Tributário, pp. 103-104. 